\title{
EXCHANGE RATE RISK PREMIUM: AN ANLYSIS OF ITS DETERMINANTS FOR THE MEXICAN PESO-USD
}

\section{Guillermo Benavides*}

\author{
Banco de México
}

(Received September 23, 2015, accepted December 27, 2015)

\begin{abstract}
The objective of this paper is to analyze what are the main determinants of the exchange rate risk premium (ERP). The empirical case is conducted for the daily Mexican peso-USD for a sample period from 2007 until 2015. According to the results the ERP is influenced by several financial variables which are the VIX, a carry trade index, the EMBI and the forward premium. These results are in line with previous results in the literature that have proven that exchange rate premia are influenced by several financial variables, which are usually considered as "proxies" of risk.
\end{abstract}

\section{Resumen}

El objetivo del presente trabajo es analizar cuáles son los principales determinantes de la prima de riesgo de tipo de cambio (ERP por sus siglas en inglés). El caso empírico se lleva a cabo para el peso -dólar diario durante un período a partir de 2007 y hasta 2015. De acuerdo con los resultados obtenidos el ERP está influenciado por diversas variables financieras que son el VIX , un índice de carry trade, el EMBI y la prima por ordenes de transacciones en contratos de derivados. Estos resultados están en línea con los resultados previos en la literatura que han demostrado que las primas de tipo de cambio son influenciados por diversas variables financieras, que por lo general se consideran como "proxies" de riesgo.

JEL Classification: C22, C53, C58, G10, G13.

Keywords: Exchange rates, Mexican peso-USD, Risk-Neutral Densities, Risk premiums.

* Banco de México. Av. 5 de Mayo 2, Centro, México, D. F., CP. 06059, México. Tel. (+52)55-5237-2000, Ext.3877. Fax (+52)5237-2687. Email: gbenavides@banxico.org.mx

The comments detailed in the present research document are those of the author and do not necessarily reflect those of Banco de México. I deeply appreciate comments from seminar participants at Banco de México and the IMEF Financial Research International Congress 2015. Special thanks are given to Enrique Covarrubias, Santiago García-Verdú, Jessica Roldán and two anonymous referees for their valuable comments. All remaining errors are my own. 


\section{Introduction}

It is recognized that the analysis of exchange rate dynamics has become a crucial financial topic, especially, in a world becoming more integrated in its international financial markets. Exchange rate movements through time may influence consumption and investment decisions from economic agents. Some of these observed fluctuations in currencies throughout the world may be related to several economic factors. Among these there are risk factors, which may be consider relevant components of exchange rate variations. A foreign exchange risk premium can be understood as the representation of the market's anticipated excess return to holding foreign currency relative to holding domestic currency (Carlson and Osler: 2003, Engle: 1992, 2012). Within this concept the exchange rate risk premium is defined as the expected future spot exchange rate minus the current forward exchange rate (Hakkio and Sibert: 1995). The difference between these two prices may justify an additional amount of money that an investor will demand in order to be compensated for an expected depreciation of a currency, in which the investor holds a long position. Another definition is that of a monetary amount that is not in line with fundamental equilibrium conditions in exchange rate markets (Frankel and Chinn: 1993; Díaz de León y Casanova: 2004), i.e. that part of the variation in a currency not currently explained by fundamental economic variables (for example, economic fundamentals can be interest rate differentials as stated by the Uncovered Interest Rate Parity). ${ }^{1}$

It is important to point out that the ERP is not a standard concept in the relevant financial literature, so there are several ways to quantify it. For different reasons, it may be important to some economic agents to quantify the previously defined exchange rate premium (ERP). A motivation to estimate the ERP is that it is an indicator number of what a representative investor 'perceives' as the monetary compensation needed for an expected depreciation of a specific currency, most of the times associated to holding long positions in currencies from emerging economies. The ERP is then a forward looking measure that shows the market's perception for quantifying an exchange rate risk. Again, this risk measure is a relevant one to look for, especially, for agents taking economic or policy decisions based upon current financial information from Foreign Exchange (FX) markets. These agents could be financial FX investors, risk managers, hedge fund managers, individual investors, policy makers, among others. In addition, from a more fundamental analysis, academic researchers could also find relevant to understand in more detail the ERP, including its dynamics from theoretical or empirical concepts.

The purpose of the present research paper is twofold. One is to estimate the ERP for the Mexican peso-USD exchange rate using novel methods applying the estimation of Risk-neutral densities, which include financial derivatives (options and forward prices). The other one is to analyze what are the main drivers of the previously mentioned ERP. In order to achive the objective related to

\footnotetext{
1 Among the main differences between the work made by Díaz de León y Casanova: 2004 and this present research document are that the former only estimated the ERP, whilst the latter, there is a more deep analysis about the ERP dynamics, specifically, there is a more detail explanation about the ERP' determinants.
} 
analyzing what are the ERP's main determinants econometric models based on linear regression a Vector Autoregression Models (VAR) are applied. These econometric models were chosen in order to provide the estimations that will show the possible statistical relationship between the variables under study. According to the estimations and the results presented in this current research document, it appears that the ERP for the exchange rate under study has been decreasing since the end of the last Great Recession. According to the results from linear regression, the variable EMBI is the one that has the highest impact on the ERP. The variable that follows (second highest impact) is the TED and then the VIX. The VAR estimations are consistent (qualitatively speaking) with the results obtained from the linear regression models. It can be concluded, according to these results, that country credit risk (represented by the EMBI) in addition to systematic risk proxy by the TED and the VIX are the most important factors (or drivers), which affect the ERP dynamics. It is then considered an additional contribution to apply a method in the present research document, which up to date, is not commonly applied for the Mexican peso - USD exchange rate. Further research about the theoretical justification of these empirical analyses are suggested for future understanding of this topic. Most of these results are in line with the literature that shows that uncertainty in financial markets (specifically financial market volatility) are the main factors that impact risk premiums including those for exchange rates. ${ }^{2}$

The layout of the rest of this research paper is as follows. Section 2 presents a formal definition of the ERP and then details about the applied methodology used to estimate the ERP including the econometric models are given. In Section 3 details about the data and regression analysis are presented. The presentation and analysis of the results are detailed in Section 4, which also includes the review of the ERP's main determinants with suggestions for further research. Finally, Section 5 concludes that the main drivers of the ERP are the EMBI and VIX variables, according to the econometric results.

\section{Exchange Rate Risk Premium Estimation}

In this section there is a detailed explanation of the Risk-Neutral density concept, which is relevant in order to estimate the ERP. Included in the RiskNeutral density explanation the Volatility Function Technique method is also presented. This latter method is used mainly for exchange rate options, given that, as it will be shown, it considers options strategy information in order to extract the expectations of the FX. Lastly, the procedure related to the estimation of the ERP is presented.

\subsection{Risk-Neutral Densities Definition}

In order to understand better the estimation of the ERP it is helpful to review the concept of Risk-Neutral Density (RND) extracted from option prices. The RND is a set of expectations, which are estimated from traded option prices and are presented in a form of a statistical density i.e. as

\footnotetext{
2 As it is known EMBI refers to the Emerging Market Bond Index, TED is the yield differential between an interbank and a risk-free interest rates for the USD and VIX refers to the S\&P 500 option implied volatility index for one-month to maturity S\&P 500 call and put options, expressed as an annualized percentage.
} 
having the entire possible (expected) distribution of the asset price. The idea to estimate RNDs implied by option prices was first postulated by Breeden and Litzenberger (1978). The main reason to do this was the belief that there is a rich source of forward-looking financial information in derivatives markets. A way to extract this information is by estimating an implicit probability distribution of an asset from the observed prices of option contracts on such an asset, which are traded in these financial markets. However, given that the models used to estimate these probabilities use an equivalent martingale measure of the objective (real) probability that prices assets as if agents were risk-neutral, the resulting probability density is called "risk-neutral density". This of course does not mean strictly speaking that investors are assumed to be risk-neutral. The RND can be extracted for any asset including currencies.

Breeden and Litzenberger (1978) proved that the RND can be extracted from the prices of call (or put) options, which are usually traded in the market. In particular the value of a call option is defined as

$$
c(X, T)=\int_{X}^{\infty} e^{-r T}\left(S_{T}-X\right) f\left(S_{T}\right) d S_{T}
$$

where, $c$ refers to the call option price, $X$ is the exercise price, $T$ is the time to maturity, $r$ is the risk-free interest rate, $S_{T}$, spot price of the underlying asset at maturity of the option and $\mathrm{f}\left(\mathrm{S}_{T}\right)$ represents the risk-neutral probability function of the price of the underlying asset. Then, by calculating the second partial derivative of the call price function $\mathrm{c}(\mathrm{X}, \mathrm{T})$, with respect to the exercise price $(\mathrm{X})$ we obtain

$$
\frac{\partial^{2} c(X, T)}{\partial X^{2}}=e^{-r T} f(X)
$$

Rearranging this expression, it is possible to obtain the following definition,

$$
f(X)=e^{r T}\left(\frac{\partial^{2} c(X, T)}{\partial X^{2}}\right)
$$

where $f(X)$ is the risk-neutral distribution.

The problem with defining $f(X)$ is the assumption that the call price function is continuous for the range of exercise prices. As it is known, this is not realistic given that in practice only some prices in discrete time are available or observed. Considering this limitation, Shimko (1993) proposed an interpolation method using the available exercise prices. In subsequent research, Malz (1997) proposed to interpolate across implied volatilities (using the framework of Garman and Kohlhagen: 1983) and the delta, which is the sensitivity of the option price with respect to changes in the underlying asset price. In this case, the delta has to pass through at least three points of the volatility smile as it will be explained in more detail in Subsection 2.1.1. One advantage of Malz's method is that it can be easily applied to exchange rate options. This is because traders trade quoting implied volatility as a function of delta. Therefore, there is always hard data available for implied volatility, which can be used for a smoother interpolation.

RNDs estimations not only give a point estimate forecast about the moments of a specific underlying asset, but also provide information about the 
whole asset price distribution expected by the market. Hence, extracting a RND provides information about market sentiment. For example, if an exchange rate shows RNDs with skewness that are systematically positive through time, the interpretation is that the market is expecting one of the currencies to depreciate (or keep depreciating) in the near future.

Considering the actual evidence, it could be assumed that, from a theoretical viewpoint, RND estimation can be seen as a parsimonious and a reliable approach for capturing the market's belief about a future asset price (or exchange rate) distribution.

\subsubsection{The Volatility Function Technique}

The volatility function technique (VFT) was originally postulated by Malz (1997). He extended the idea proposed by Shimko (1993), in which, the application of interpolation methods to exercise prices allows to recover the RND. Shimko's method suggested a parabolic function to estimate a curve for the implied volatility function vis-à-vis exercise prices; i.e., the smile curve. The idea behind this method is to estimate a "smoothed" smile implied volatility function, out of a relatively few exercise prices (five or less) with a parabolic function, and then generate smooth call option prices using the Black and Scholes (1973) formula (BS).

Several studies have applied the VFT. For example, Bliss and Panigirtzoglou (2002) extracted RNDs for the FTSE-100 stock index and short sterling futures. After an extensive comparison with other estimation methods, they concluded that the VFT approach shows better goodness-of-fit and stability of the parameters. However, they found that the tails of the RNDs were significantly unstable for the methods they analyzed (VFT and the mixture of lognormals). Similarly, Benavides and Mora (2008) found qualitatively similar results for both methods, but applied for the Mexican Peso-USD exchange rate. This concept is not innocuous given that an unstable tail could make difficult the Value-at-Risk analysis. The principal difference between Benavides and Mora (2008) paper and the present research document is that, the former, does not estimates the ERP whilst for the latter, there is a methodological procedure to estimate the ERP. On the other hand, Mc Manus (1999) found that the VFT was not as accurate as the mixture of lognormals' method, which showed higher goodness-of-fit for the case of Eurodollar options. Micu (2004) extracted RNDs for twelve emerging markets currencies vis-à-vis the US Dollar. Among other methods, he applied the VFT method and concluded that there is a tradeoff between goodness-of-fit accuracy and stability of the parameters. Castrén (2005) used this method to examine RNDs for Eastern European currencies on days of economic releases. It is worthwhile to mention that the literature related to extracting ERP from RNDs is relatively scarce. ${ }^{3}$

To understand this procedure with more detail it is convenient to refer to the equivalent Black and Scholes (BS) model for exchange rates, which was

\footnotetext{
3 See for instance Abarca et al. (2013) for an approximation for the estimation of ERP for several emerging market currencies. The interested reader is also refer to Díaz de León y Casanova (2004) for a more detail explanation of the estimation of ERP for the Mexican peso - USD exchange rate.
} 
postulated by Garman and Kohlhagen (1983), henceforth, GK. The underlying assumptions of this option valuation model for exchange rates are the following: 1) interest rates are non-stochastic; 2) there are no arbitrage profits; 3) all options are European-style; 4) agents are risk-neutral; 5) there are no transaction costs or taxes; and 6) the price for the underlying asset follows a Geometric Brownian Motion. While some of these assumptions appear quite strong, there is still interest to apply such models to estimate RNDs. This is because these approximations provide useful information about market expectations that could give us some feedback about dynamic features of a specific financial asset, especially around an economic event. ${ }^{4}$

To calculate the implied RND using the GK model, it is required: the foreign risk-free interest rate $r_{f}$, in addition to the previously defined inputs $(r$, $T, S, X$,$) and the market price of either a call option or a put option. The GK$ model is therefore:

$$
\begin{gathered}
c(X, T)=S e^{-r_{f} T} N\left(d_{1}\right)-X e^{-r T} N\left(d_{2}\right), \\
p(X, T)=X e^{-r T} N\left(-d_{2}\right)-S e^{-r_{f} T} N\left(-d_{1}\right)
\end{gathered}
$$

,

$$
\begin{aligned}
& d_{1}=\frac{\ln \left(\frac{S}{X}\right)+\left(r-r_{f}+\frac{1}{2} \sigma^{2}\right) T}{\sigma \sqrt{T}}, \\
& d_{2}=d_{1}-\sigma \sqrt{T}
\end{aligned}
$$

where $c$ is the value of the European-style call option, $p$ is the value of the European-style put option, $N(x)$ is the cumulative normal distribution, and $\sigma^{2}$ is the annualized price-return variance. If observed option prices in the market are used instead of the theoretical ones, it is possible to implicitly extract the probability distribution that was relevant for the agents when they traded the options. Assuming that $c, p, S, X, r, r_{f}, T$ in Equations 4 and 5 are observed, and after making an assumption about the value of $\sigma$ (implied volatility), the RND can be implicitly estimated following Equation 3. In this research project, implied RNDs are derived from nearby to expiration over-the-counter three month option contracts on the MXN-USD exchange rate for each trading day. Thus, instead of assuming a standard cumulative normal $N(x)$, as it is shown in Equations 4 and 5 above, the RND is implicitly extracted from the model using the observed option values with the additional variables.

With the estimated call and put prices, the RND can be extracted by applying the previously defined Breeden and Litzenberger (1978) approach. The main difference with respect to Shimko's method is that the Malz's model does not use a parabolic function to estimate the smile curve, but instead it applies implied volatilities from option pricing strategies (risk reversals and

\footnotetext{
4 For a research about the changes in the shape of the RNDs around a relevant monetary policy event the interested reader is refer to Abarca, Benavides and Rangel (2012).
} 
strangles)..$^{5}$

The objective is to estimate a curve matching implied volatility vis-à -vis the delta and then calculate the call option prices from it by using either BS or GK. ${ }^{6}$

The approach of Malz (1997) estimates a RND by interpolating the smile curve. Specifically, interpolation can be carried out in terms of the implied volatilities determined from market expectations. The considered implied volatilities are: 1) at-the-money ( $\mathrm{atm})$, where the forward price ( $F$ ) equals the exercise price; 2) risk reversal ( $r r)$; and 3) strangle (str). For exchange rates these were taken from market traders. The implied volatilities from the above mentioned option strategies for a 25 delta call and put option can be theoretically obtained as follows. Let $r r$ be defined as,

$$
r_{t}^{25 \triangle}=\sigma_{t}^{\left(\triangle_{0.25}^{c}\right)}-\sigma_{t}^{\left(\triangle_{0.25}^{p}\right)}
$$

and str as

$$
\operatorname{str}_{t}^{25 \triangle}=0.5\left[\sigma_{t}^{\left(\triangle_{0.25}^{c}\right)}+\sigma_{t}^{\left(\triangle_{0.25}^{p}\right)}\right]-\sigma_{t}^{A T M} .
$$

Then, writing the volatility as a quadratic function of delta $(\delta)$, it is possible to obtain the following smile curve: ${ }^{7}$

$$
\sigma(\delta)=a t m-2 r r(\delta-0.5)+16 s t r(\delta-0.5)^{2}
$$

Once this curve is obtained a transformation is performed in which the implied volatility can be expressed in terms of exercise price $X$ and not in terms of the delta. Thus, the definition of the delta function is now as follows:

$$
\delta=e^{-r f T} * N\left(\frac{\ln \left(\frac{F_{t}}{X}\right)+\left(\frac{\sigma^{2}}{2}\right) T}{\sigma \sqrt{T}}\right)
$$

\footnotetext{
5 A risk reversal is an option trading strategy that is constructed with an out-of-themoney (OTM) long position of a call option and an OTM short position of a put option, both with the same time to expiration (the investor is hoping for extreme increases in the exchange rate to make a profit). A strangle is another common currency option trading strategy, which consists in taking an OTM long position of a call option and an OTM long position of a put option, both with the same time to expiration (the investor is hoping for extreme movements in either direction of the exchange rate to make a profit). The options are OTM given that these are cheaper.

6 Malz argued that his method is more accurate for modeling financial data given that option strategies' implied volatilities, like risk reversals and strangles, capture the market's expectations for the relative likelihood of exchange rate depreciations (implied skewness) and extreme events (excess implied kurtosis).

7 The $\delta$ is defined as the sensitivity of the option price to a change in the spot price. In other words, for an option valuation function it is the first derivative of the option price with respect to the underlying asset price.
} 
where $F_{t}$ is the forward price. Equation 9 is substituted into Equation 8 and then Equation 10 below is obtained,

$$
\sigma(\delta)=a t m-2 r r\left(e^{-r f T} * a_{1}-0.5\right)+16 s t r\left(e^{-r f T} * a_{1}-0.5\right)^{2}
$$

where $F_{t}$ is the forward price. Equation 9 is substituted into Equation 8 and then Equation 10 below is obtained, where $a_{1}$ is equal to $N\left(\frac{\ln \left(\frac{F_{t}}{X}\right)+\left(\frac{\sigma^{2}}{2}\right) T}{\sigma \sqrt{T}}\right)$. To estimate the density function for the underlying asset the Breeden and Litzenberger (1978) result is applied here. Thus, by substituting these expressions into Equation 3, it is then possible to estimate the probability function for the underlying asset, which is expressed as follows:

$$
\begin{aligned}
& f\left(S_{T}\right) \\
& =e^{r T}\left[F\left(b_{1}+n\left(d_{1}\right) d_{1}\left(\frac{1}{X v \sqrt{T}}\right)^{2}\right)-X\left(b_{2}+n\left(d_{2}\right) d_{2}\left(\frac{1}{X v \sqrt{T}}\right)^{2}\right)\right]
\end{aligned}
$$

where $b_{1}$ is equal to $\left(\frac{n\left(d_{1}\right)}{X^{2} v \sqrt{T}}\right)$, and $b_{2}$ is $\left(\frac{n\left(d_{2}\right)}{X^{2} v \sqrt{T}}\right)$

$$
\begin{array}{r}
d_{1}=\frac{\ln \left(\frac{F_{t}}{X}\right)+\left(\frac{\nu^{2}}{2}\right) T}{v \sqrt{T}}, \\
d_{2}=\frac{\ln \left(\frac{F_{t}}{X}\right)+\left(\frac{\nu^{2}}{2}\right) T}{v \sqrt{T}},
\end{array}
$$

$n(x)$ is the normal density function and $v$ represents the option implied volatility, which makes Equation 10 equals to zero. Finally, by using different values of $X$, it is then possible to extract the RND through option prices.

\subsection{Exchange Rate Risk Premium}

As explained in the introduction, the idea behind quantifying the ERP is related to that amount of money investors should be compensated given systematic depreciations of a currency they hold as a long position. The reasoning is as follows (the following explanation is basically rephrasing the research document of Díaz de León and Casanova: 2004): in efficient markets assuming perfect capital mobility and uncovered interest parity the following equilibrium condition must hold (Frenkel: 1995).

$$
r_{t, T}=r f_{t, T}+E_{t}(d e p)+\delta_{t, T}
$$

where $E_{t}(d e p)$ refers to the expected depreciation of the Mexican peso and $\delta_{t, T}$ is the ERP. This last component is related to market inefficiencies in which, there is a skewness toward depreciation of one of the currencies. Basically, the ERP is that bias towards the depreciation of one of the currencies that in most of the cases, is the one of the emerging economy with respect to the developed 
one. The rest of the notation is the same as stated above. It is known that the standard formula for a currency forward, given no-arbitrage pricing is (Hull: 2013),

$$
F_{t, T}=S * \exp \left[r_{t, T}-r f_{t, T}\right] T-t,
$$

where notation is as given above. By combining the last two equations it is possible to obtain,

$$
r_{t, T}-r f_{t, T}=\ln \left(F_{t, T} / S\right)=E_{t}(d e p)+\delta_{t, T},
$$

It can be seen from the above expression that the implied depreciation on forward contracts is determined by the difference between internal and external interest rates. This measure alone does not correspond to the expected depreciation of the exchange rate considering the presence of the exchange risk premium $\left(\delta_{t, T}\right)$. This shows why the probability functions of risk-neutral densities shown for some currencies (e.g. Mexican peso / US Dollar) have a systematic implicit bias (skewness), since, in the absence of risk premiums referred $\left(\delta_{t, T},=\right.$ 0 ), the distribution that would be exhibiting would be closer to the lognormal distribution as states by option pricing theory (see Hull: 2013). Therefore, a way to estimate the exchange risk premium would be as detailed in Díaz de Le ón and Casanova (pg. 38) "the percentage difference between the mean of the probability distribution based on observed data and its corresponding lognormal distribution (with risk reversals and strangles strategies equal to zero). This implies that the proposed premium corresponds to the additional yield that should be received by a risk-neutral investor by maintaining an asset denominated in a weak currency (pesos) with a bias to its depreciation (that offers a lower expected return in foreign currency - US dollars)." As detailed in the subsection 2.1., in which the estimation method for the RNDs of Malz (1997) was explained, measures of risk-reversal and strangle represent the skewness and kurtosis in the distribution respectively (RND). Graph 1 shows graphic details about the ERP extraction. 
Graph 1. Estimation of the Exchange Rate Risk Premium from Lognormal and Option Implied Densities

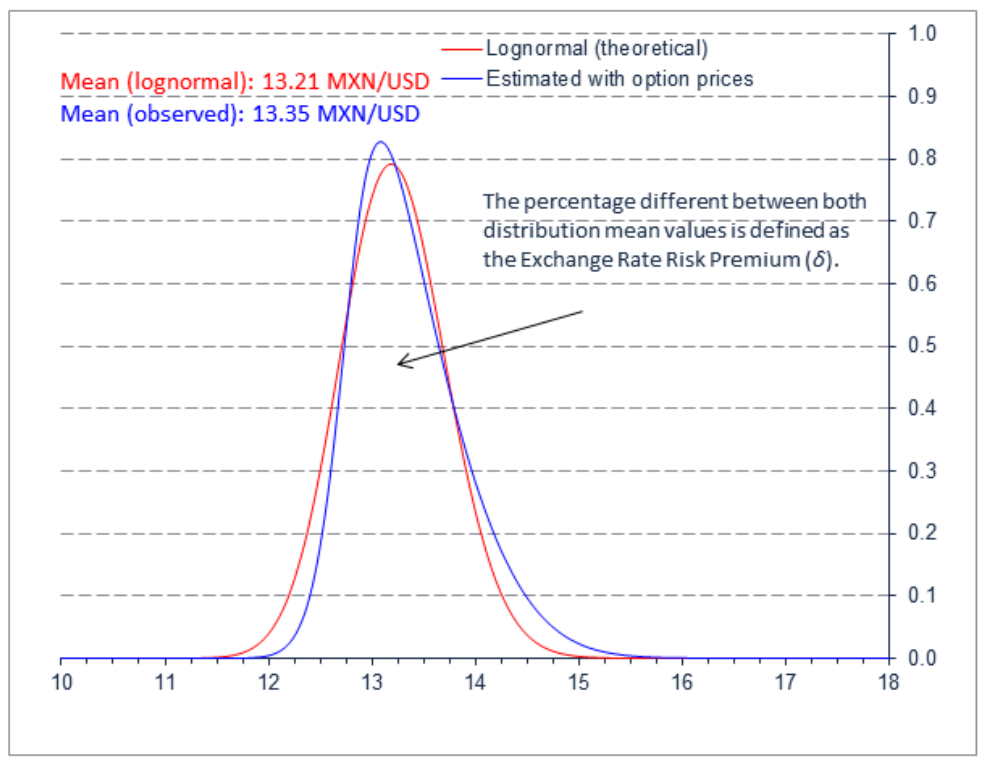

Source: Own estimations with data from Bloomberg and UBS.

As it can be observed in that figure, the ERP can be estimated as the percentage difference of the mean values of the previously mentioned probability densities (lognormal and the RNDs). Thus, ERP can be extracted implicitly from information about exchange rate option prices. ${ }^{8}$

It is important to point out, that the estimation of the ERP is based in a parsimonious approach related to interest rate parity. It is understood that there may be other risk premiums related to Equation 12, possibly related to currency liquidity or counterparty risk, however, since the Mexican peso is a relatively highly traded currency (there are Mexican peso futures contracts at the Chicago Mercantile Exchange), it is assumed that the liquidity risk is relatively small. Also, it is assumed that counterparty risk is close to zero given that in the wholesale market for the Mexican peso, most of the trading is carried out by well-established financial institutions.

Most of the data for the estimations are from the Bloomberg database. There are 2 time frames under study. One is the sample period from $01 / \mathrm{Jan} / 2007$ until $18 / \mathrm{Jun} / 2015$, which are 2,202 daily observations and the other one is from 31/Dec/2009 until 18/Jun/2015, which includes 1,256 daily observations. The time frames are chosen considering data availability,

\footnotetext{
8 ERP can be expressed as the difference in the expected values of a risk-neutral density and a subjective density. The former is extracted from information implicit in option prices, whilst the second one, is an assumed distribution for the underlying (exchange rate) price. ERP are relevant for a specific time horizon, in this case 3-month time-to-maturity are considered.
} 
specially, for Mexican peso - USD options and options strategies. For the second time frame the sample period used was chosen considering order flow data availability .The data variables that are downloaded from Bloomberg are the Mexican pesos - USD spot and forward exchange rates, VIX, TED spread, carry trade index, which is the ROCI index calculated by Credit Suisse and the EMBI index, which is calculated by JP Morgan. The order flow data (net long vs short positions) are taken from the Chicago Mercantile Exchange (CME), which is available at the CME's webpage. ${ }^{9}$

The option strategies exchange rate data, which are at-the-money, riskreversals and strangle implied volatilities were obtained from a dataset of the investment bank UBS. ${ }^{10}$ These implied volatilities direct quotes are a weighted average of major operations that UBS and other financial institutions conducted in the Mexican peso-USD currency option over-the-counter market. According to the information obtained the procedure is that UBS obtains a poll of several relevant transactions and provide a representative reading of what it was the market for that exchange rate. The quotes in units called vols follow the conventions usually expressed by exchange rate dealers. The UBS database is available for subscribers only. At-the-money implied volatility is for a delta of 50 , and risk-reversal and strangles are those considered with a 25 delta. As it is known in the financial industry, these are the most common and liquid ones in that type of trading ( 25 delta). We are using implied volatilities for three-month maturity considering that they are also the ones that show more significant trading in terms of volume and there are usually data availability on a daily basis for all these type of option strategies. Other maturities often present "blanks" or missing data value for certain days.

\subsection{Analyzing the Exchange Rate Risk Premium (ERP Decomposition)}

As mentioned above, in the present research paper estimates of the ERP are found as a percentage difference in the mean values (expected values) between the VFT density and a lognormal density with the same mean and standard deviation following the procedure explained in more detail in Díaz de Leon and Casanova (2004). ${ }^{11}$

As it is has been mentioned previously an additional contribution to apply a method in the present research document, which up to date, is not commonly applied for the Mexican peso - USD exchange rate. Graph 2 shows the 3-month ERP estimated with the previously mentioned methodology including the spot exchange rate Mexican peso-USD.

\footnotetext{
9 The CME webpage is http://www.cmegroup.com/

10 The implied volatility data are taken from quotes made on volatility trading and not over option prices. In other words, it is hard data for exchange rate volatility. It is common practice among option traders to trade with volatility quotes in exchange rate option markets (See Malz (1997); Cooper and Talbot (1999) for more details).

11 It is worthwhile to point out that the VFT method is considered a non-parametric method, whilst the lognormal density, is a parametric one.
} 
Figure 2. Mexican Peso Exchange Rate Spot (pesos per dollar) and Risk Premium (percentages)

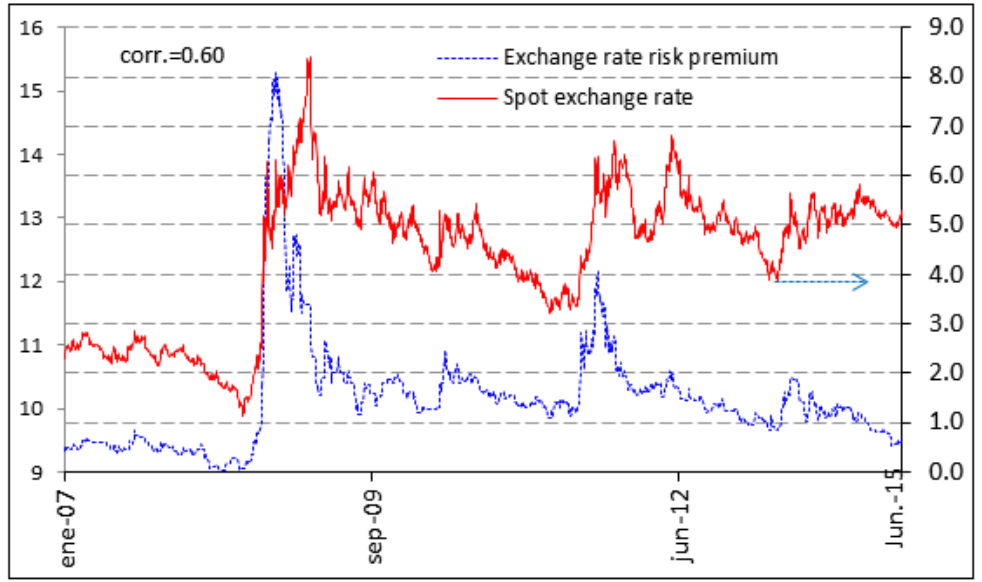

Source: Own estimations with data from Bloomberg and UBS.

It can be observed in that graph the high ERP associated with the 20082009 Financial Crisis, in which, the Mexican peso suffered a relatively high depreciation of about 19\% during October, 2008. Another relevant peak occurs around September 2011, which is associated with a tough moment of the Greek Financial Crisis. Those events brought high uncertainty to financial markets and above-normal depreciations were observed, especially, for emerging economies' currencies. After those episodes it looks like the ERP has diminish in terms of its level, with the exception of May, 2013 that it is associated with the "Taper Tantrum" and the financial volatility around that date. ${ }^{12}$ During most of 2014 the ERP has been in relatively low levels if compared with the whole sample under analysis. Lastly, Graph 3 shows the ERP decomposition considering Equation 14 above.

\footnotetext{
12 It is worthwhile to point out that around that time the VIX (implied volatility) index for the S\&P 500 showed a similar pattern.
} 
Figure 3. Exchange Rate Risk Premium Decomposition (Basis Points).

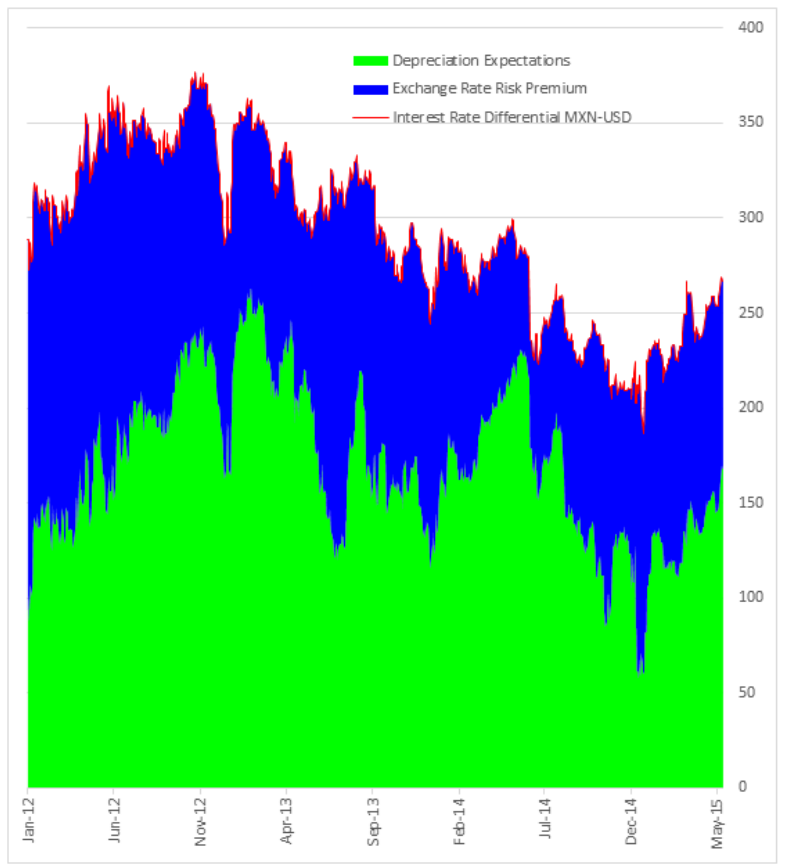

Source: Own Estimations with Data from Bloomberg and UBS.

In this graph the ERP is for a period of three-months, i.e. $\mathrm{T}=0.25$. In other words, in this graph it is possible to observe the ERP components, which are the nominal interest rate differentials between Mexico and the US, in addition to, the expected depreciation of the Mexican peso. As it can be observed in this figure from 2012 onwards the ERP has been overall diminishing, whilst, the expectation for a Mexican Peso depreciation have been increasing relatively with respect to the other variables. Apparently, during periods of higher exchange rate volatility i.e. the FED "Taper Tantrum" around May, 2013 the ERP tends to increase relative to depreciation expectations. This is in line with that part of the academic literature, in which, is documented the positive relationship between those variables (Carlson and Osler: 2003, Engle: 1992, 2012). Also, it is possible to observe that the volatility of the ERP, measured as its range of variation (variance of the series) has been decreasing through time. Apparently, the ERP has been relatively more stable recently, specially, if it compared with values before 2010 .

\section{Determinants of the Exchange Rate Risk Premium}

In the following section, an analysis of the determinants of the ERP is carried out. The procedure is as follows: First there is a brief description of some research documents available in the literature, in which, there are ERP related models i.e. linear regression in which the ERP is part of an Equation. Second, linear regression models are presented in order to show what variables could be the main drivers of ERP. Lastly, an analysis of the estimated results (from the linear regression) are analyzed and documented. 


\subsection{Regression Analysis}

It is known in the literature that several factors affect the ERP. For example, Carlson and Osler (2003) identify factors related to non-speculative activity of FX dealers, speculator's risk aversion and volatility in relevant financial variables, among others. Similarly, Engle $(1992,2012)$ shows in his analysis of the FX risk premium, that financial variables are relevant variables in order to explain the dynamics of the previously mentioned risk premium and the "forward rate puzzle". In the present research document in order to look for the determinants of the exchange rate risk premium several factors will be consider to look for possible statistical relationships between the previously mentioned variables. These factors or financial variables are chosen following Carlson and Osler (2003) and Engle (2012, 1992), whom document about the relevant drivers about the ERP. In this present research document the variables included for the statistical analysis are related to volatility in financial markets as well as interest rate differentials and FX order flows, which can represent trading activity by FX dealers. Graph 4 shows the relevant time series under study and Table 1 details it descriptive statistics.

Graph 4. Time Series under Analysis.
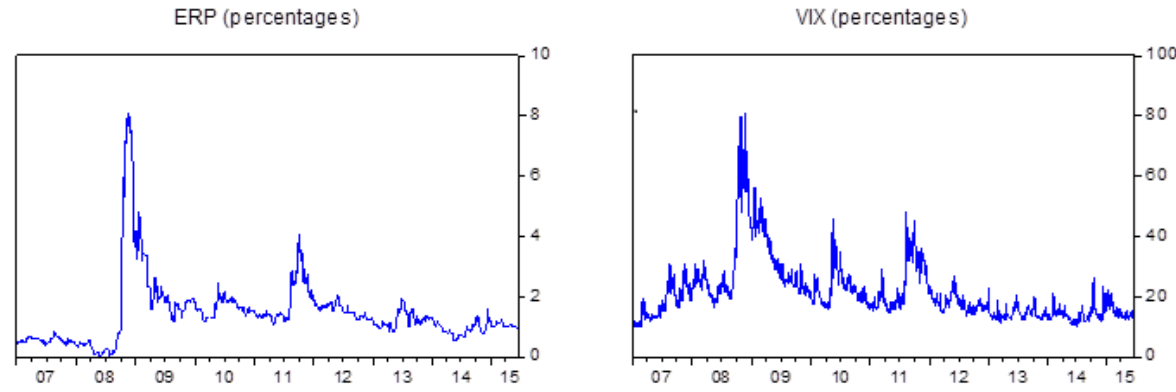

TED (percentages)
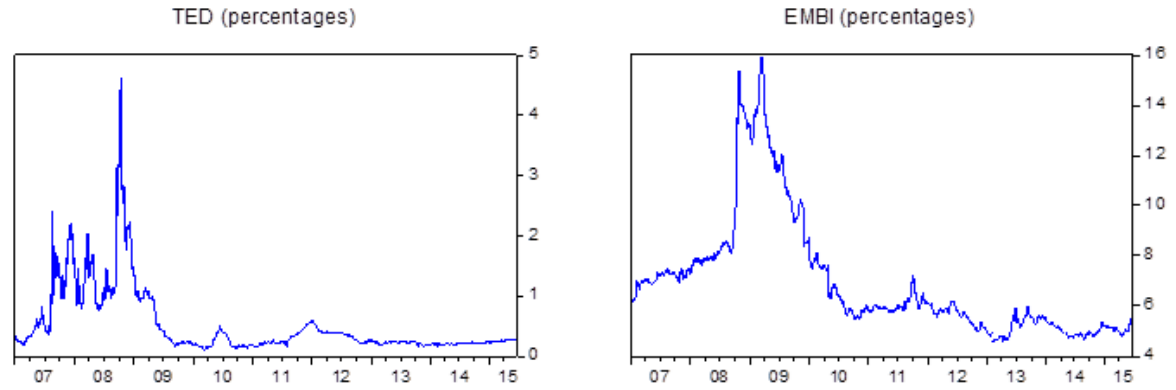
Graph 4. Time Series under Analysis. (Continued)
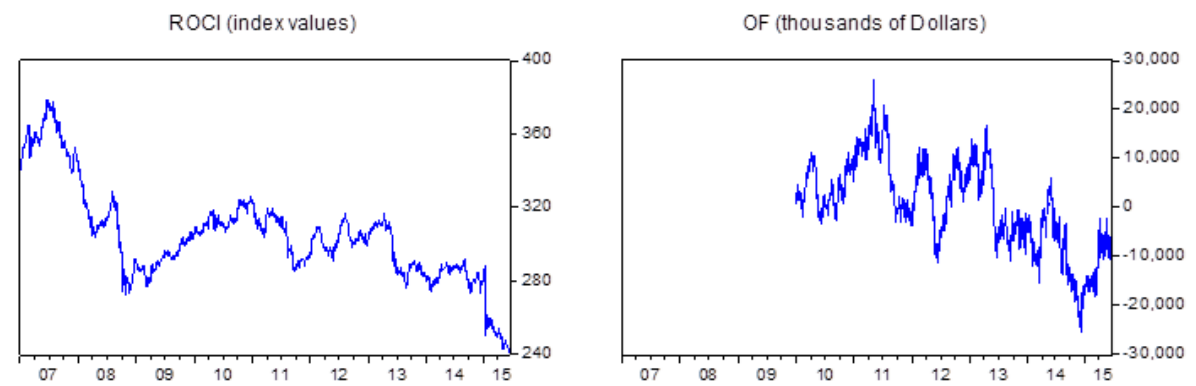

Notation is as follows: ERP represents the exchange rate risk premium, VIX is the implied volatility index from option prices for the S\&P500, TED is the differential between the interbank interest rate and the risk free interest rate for US Dollars. EMBI stands for Emerging Market Bond Index, ROCI represent the carry trade index and OF stands for order flow (net long and short positions) for the Mexican Peso futures contracts traded at CME. Source: UBS, Bloomberg and Chicago Mercantile Exchange (CME).

Table 1 Descriptive statistics.

Time frames: January, 2007 - June, 2015 and January, 2009 - June, 2015

\begin{tabular}{|l|r|r|r|r|r|r|}
\hline & ERP & \multicolumn{1}{|c|}{ VIX } & \multicolumn{1}{l|}{ TED } & \multicolumn{1}{c|}{ EMBI } & \multicolumn{1}{l|}{ ROCI } & \multicolumn{1}{c|}{ OF } \\
\hline Mean & 1.47 & 21.98 & 0.54 & 7.11 & 308 & 2,361 \\
\hline Median & 1.32 & 18.94 & 0.27 & 6.14 & 305 & 2,153 \\
\hline Maximum & 8.10 & 80.86 & 4.64 & 15.90 & 378 & 26,016 \\
\hline Minimum & 0.02 & 9.89 & 0.11 & 4.57 & 272 & $-19,284$ \\
\hline Std. Dev. & 1.15 & 10.38 & 0.59 & 2.46 & 23 & 7,819 \\
\hline Skewness & 2.88 & 2.10 & 2.73 & 1.64 & 1.13 & -0.01 \\
\hline Kurtosis & 14.46 & 8.59 & 12.67 & 5.07 & 3.83 & 2.61 \\
\hline Jarque-Bera Stat. & 13,979 & 4,152 & 10,471 & 1,279 & 494 & 8.06 \\
\hline Probability & 0.00 & 0.00 & 0.00 & 0.00 & 0.00 & 0.02 \\
\hline Observations & 2,039 & 2,037 & 2,039 & 2,039 & 2,038 & 1,256 \\
\hline
\end{tabular}

Source: Own Estimations with Data from Bloomberg and UBS. Notation is the same as given in Graph 4.

To achieve the previously mentioned objective a linear regression model in addition to a VAR model will be applied. The application of these type of models is mainly motivated by empirical facts that the Mexican peso - USD exchange rate reacts significantly to movements in other relevant financial variables. Considering previous empirical evidence plus research works available in part of the literature (for example refer to Benavides and Capistrán: 2012), which have documented the relationship of the MXN/USD exchange rate to movements in other key variables the following regression model is suggested:

$$
\begin{aligned}
\Delta E R P_{t, T} & =\alpha+\beta_{1} \Delta V I X_{t}+\beta_{2} \Delta T E D_{t}+\beta_{3} \Delta \text { Carry }_{t} \\
& +\beta_{4} \Delta E M B I_{t}+\beta_{5} \Delta O F_{t}+u_{t},
\end{aligned}
$$


where ERP represents the exchange rate risk premium, VIX is the well-known one-month ahead implied volatility measure for the Standard and Poors 500 index, TED corresponds to the TED spread, which is basically the difference between an interbank and a risk free interest rate for the USD, Carry stands for a carry trade index that shows the return potential obtained by an investor by borrowing in low yield currency and then convert and invest in a higher yield currency. EMBI is the emerging market bond index estimated and published by JP Morgan, which measure the sovereign risk of an economy (quantified by the yield differential between the emerging economy and the US risk-free rate) which in this case, is a proxy for sovereign risk given that it shows the difference between a weighted average country's return and the US risk-free rate. Finally, order flows refer to the net investor's positions in the futures market for the MXN/USD in the Chicago Mercantile Exchange, a proxy for market liquidity for this exchange rate. The last term $u_{t}$ represent a vector of errors which is assumed Gaussian. $\Delta$ represents daily change (first differences of the daily frequency series) in the variable. It could be the case that there may be a problem of endogeneity related to the independent variable about order flows (OF). This last one given that it could be highly sensitive to variations in the exchange rate. However, regressions which omitted this last component were run and there were no qualitatively differences in the results if compared with the original (suggested) regression (results available upon the reader's request). Also, a VAR model was applied for robustness check and in that specification all variables are assumed endogenous and estimated within a system of equations.

The above presented econometric model is motivated by the intuition that exchange rates are sensitive to uncertainty in financial capital markets, which in this case is proxy by the VIX, the uncertainty in money markets that is proxy by the TED spread, relevant returns obtained by currency-investing strategies (carry trade strategies), sovereign risk and by the expectations that the currency value is not in line with fundamentals about exchange rate determination, which should be captured again by a carry trade index and by the high frequency exchange rate dynamics (specially for speculative positions) that in this case is proxy by MXN/USD order flows. It is important to mention that some relevant conclusions observed in research documents highlight the importance of order flow to predict high-frequency exchange rate movements (Carlson and Osler: 2003; Evans and Lyons: 2002). Thus, the latter proxy variable is included in the present analysis. ${ }^{13}$

\subsubsection{Vector Autoregression (VAR) Analysis}

In order to analyze the statistical relationship between the above presented variables within a framework, in which, all variables are allowed to be endogenous a VAR model is also estimated. This will allow each variable to depend of its past own values (lagged) and the other variables in the model been also lagged. With the estimation of a VAR model will then be possible to estimate impulseresponse functions (through Cholesky variance decomposition), which may give

\footnotetext{
13 It should be mentioned that Equation 15 is not directly related with Equation 14 given that, the latter, is a way to define the ERP, whilst the former, is an enconometric model aiming to explain the correlations between ERP and relevant financial variables given some insights seen in the relevant academic literature.
} 
more details about the dynamics between these variables, especially, with respect to the ERP. In general, the unstructured VAR model can be expressed in matrix notation as in Equation 16 below.

$$
x_{t}=A_{0}+A_{1} x_{t-1}+\ldots+A_{p} x_{t-p}+B_{0} z_{t}+B_{1} z_{t-1}+\ldots+B_{r} z_{t-r}+\varepsilon_{t},
$$

In this representation $\mathrm{x}$ is a vector of variables in the system. $\mathrm{A}_{0}$ represents a $\mathrm{n}$ $\mathrm{x} 1$ vector of intercept terms. $\mathrm{A}_{1}, \ldots, \mathrm{A}_{p}$ represent $\mathrm{n} \times \mathrm{n}$ matrices of coefficients, which relate the lagged values of the variables, which are endogenous with the current values of those variables. $\mathrm{B}_{0}, \ldots, \mathrm{B}_{r}$ represent $\mathrm{n} \times \mathrm{m}$ matrices of coefficients which relate lagged and current values of the variables which are exogenous to current values of the endogenous variables. Finally $\varepsilon_{t}$ represent a $\mathrm{n} \times 1$ vector of error terms. The coefficients in this specific unstructured VAR specification are estimated within a system and solved. It is then possible to see the statistical relationship between the proposed variables having all of them as endogenous i.e. interacting between each other in a statistical paradigm showing its dynamics given the lags. The optimal number of lags in the model were obtained by using 'Information Criteria' specifically the Schwarz Bayesian Information Criterion, SBIC hereafter.

To estimate the RNDs, we use the domestic risk-free discount rate, which consists of daily 28-day secondary market interest rates of Mexican Certificates of Deposit (CDs) obtained from the same source. US CDs were obtained from the FED web page with the same maturity in order to include the equivalent foreign risk-free discount rate in the RNDs estimations (see Equations 4-7 above). ${ }^{14}$ We chose these interest rates because they are highly liquid in the secondary market and we can find the relevant maturity for our study, i.e. 3month ahead. These interest rates are inputs in the formulae presented above for both methods.

\section{Analysis of the Estimated Results}

In the following application two regressions are run related to Equation 15. The first one is basically that same equation (same specification of Equation 15) but the order flow variable is not included. The reason not to include that variable is because it does not have a sufficiently long time series of data (historical). For example, the OF variable from that source and database starts until 2009. Also, there may be a chance that by including the OF variable, there can be an endogeneity problem. According to those results, we can observe that the exchange rate risk premium is statistically significantly influenced by all the variables included in the specification from Equation 15. As it can be observed in Table 2 the one that has most of the influence on the ERP is the EMBI, given that it is the coefficient with the highest magnitude (approx. 0.1011).

14 The FED webpage is: www.federalreserve.gov 
Table 2. Econometric Results for Equation 15.

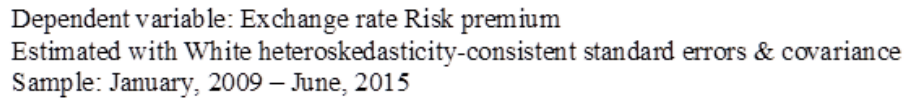

\begin{tabular}{lrrrr}
\hline \hline Variable & Coefficient & Std. Error & t-Statistic & \multicolumn{1}{c}{ Prob. } \\
\hline \hline C & -0.0013 & 0.001940 & -0.6748 & 0.4999 \\
D(VIX) & 0.0129 & 0.001168 & 11.0317 & 0.0000 \\
D(ROCI) & -0.0080 & 0.001432 & -5.5811 & 0.0000 \\
D(EMBI) & $\mathbf{0 . 1 1 7 3}$ & $\mathbf{0 . 0 2 3 1 2 1}$ & $\mathbf{5 . 0 7 5 0}$ & $\mathbf{0 . 0 0 0 0}$ \\
\hline \hline & 0.1078 & Mean dependent var & -0.0018 \\
R-squared & 0.1062 & Standard dev. dependent var. & 0.0839 \\
Adjusted R-squared & &
\end{tabular}

Source: Own Estimations with Data from Bloomberg and UBS. Notation is the same as given in Graph 4.

Given that all these estimations are carried out with percentage changes all these units are statistical comparable. In addition, Wald tests were carried out in order to see statistical difference between estimated parameters and it was shown that these estimated coefficients are statistically different between each other. Also, the results overall show consistency in terms of the signs. For example, the carry trade index shows a negative sign, which indicates that an increase in the value of that index. i.e. carry trade strategies becoming more profitable then it follows that the ERP must decrease. This result is intuitive given that it is expected that as traders are benefiting with an increase in the carry trade returns, the emerging market currency must appreciate in value driven by a higher demand for the emerging market currency, therefore, a decrease in ERP is in line with what it is expected.

The estimation was carried out with White heteroskedasticity-consistent standard errors and covariance, given that, there were indications of heteroskedasticity in the residual vector, after performing relevant heteroskedasticity tests (ARCH-LM, White, Breush-Pagan). For the other regression, which includes the order flow variable, it can be observed that the results are qualitatively similar to those in the previous regression (the one with the longer sample size). As we can observe in Table 3, the highest in magnitude coefficient is the change in the EMBI variable,which is consistent with the previous result in the above mentioned specification. 
Table 3. Econometric results for Equation 15 including the order flows variable (OF).

\begin{tabular}{|c|c|c|c|c|}
\hline Variable & Coefficient & Std. Error & t-S tatistic & Prob. \\
\hline $\mathrm{C}$ & -0.0004 & 0.0018 & -0.2244 & 0.8225 \\
\hline $\mathrm{D}(\mathrm{VIX})$ & 0.0133 & 0.0036 & 3.6428 & 0.0003 \\
\hline $\mathrm{D}$ (ROCI) & -0.0010 & 0.0035 & -2.7739 & 0.0056 \\
\hline D(EMBI) & 0.1338 & 0.0674 & 1.9849 & 0.0474 \\
\hline $\mathrm{D}(\mathrm{OF})$ & $-3 \times 10^{-6}$ & $1.36 \times 10^{-6}$ & -2.2795 & 0.0228 \\
\hline R-squared & 0.1855 & dependent & & -0.0005 \\
\hline Adjusted R-squared & 0.1829 & lard dev. des & tvar. & 0.0682 \\
\hline
\end{tabular}

Source: Own Estimations with Data from Bloomberg and UBS. Notation is the same as given in Graph 4.

Again, since all the variables in the specification enter as percentage changes all these are comparable in terms of interpreting them. The second and third coefficients order of magnitudes are those for the VIX and the ROCI index regressors. The order flow variable, although statistically significant, it is relatively small in magnitude. Given that all the estimated coefficients are statistically different from zero (as seen with it reported p-values), it can be concluded that the change in the perceived country risk, proxy by the EMBI, apparently is the variable that has the highest impact (statistically significant) on the dynamics of the exchange rate risk premium. Given that the VIX do also have relevant in magnitude coefficients (they are the second in magnitude), it can be concluded that th e ERP is mostly driven by financial risk factors associated with country risk (EMBI), financial distress measured by the interest rates differential (TED), which does not appear in the final regression estimation given that the estimated coefficient was not statistically significantly different from zero and the market's perceived volatility extracted from S\&P500 futures options (VIX). In terms of the economic meaning of these results, it can be concluded that they are in line with a priori expectations given the information available in the relevant academic literature. For example, the variable which has a higher impact on the ERP is the one related to sovereign risk (EMBI). Given that Mexico is classified as an emerging economy it makes sense to relate the value of its exchange rate to its sovereign-debt default risk. In addition, having the VIX also as a relevant statistical significant variable is in line with the argument that financial markets around the world are becoming more integrated, thus, international financial volatility proxy by the VIX is a relevant variable affecting the Mexican exchange rate, specifically the ERP. Finally, it is important to mention that the final regression specification reported (Table 2) is the one that has a sample size starting in January 2009 and not January 2007. This is for the fact that there is evidence of a structural break in the estimated coefficients once the Andrew-Quandt test for structural breaks was carried out. The break according to the previously mentioned econometric test occurred at the end of 2008 , therefore, the final regression estimation considers the sample size starting in January 2009. 
74 Nueva Época REMEF (The Mexican Journal of Economics and Finance)

\subsection{Robustness Checks (VAR Estimation and Analysis)}

In order to perform robustness checks about the above mentioned results a VAR model given the specification in Equation 16 is estimated. As it is known about VAR models all the variables are estimated within a system of equations and all of them are considered endogenous. For this specific case, the order of the VAR is two (two lags) and the decision about the number of lags was decided from information criterion, specifically, the Schwartz-Bayesian Information Criterion (SBIC). The latter is a standard method for choosing the optimal number of lags in time series models. As it can be observed in Table 4 and Graph 5 the VAR model shows qualitatively similar results as the previous linear regressions.

Table 4. VAR Results.

\begin{tabular}{|c|c|c|c|c|}
\hline & $\mathrm{D}(\mathrm{ERP})$ & $\mathrm{D}(\mathrm{VIX})$ & $\mathrm{D}(\mathrm{ROCI})$ & $\mathrm{D}(\mathrm{OF})$ \\
\hline $\mathrm{D}(\mathrm{ERP}(-1))$ & $\begin{array}{l}0.0541 \\
(0.0310) \\
{[1.742]}\end{array}$ & $\begin{array}{c}2.4062 \\
(0.7658) \\
{[3.1438]}\end{array}$ & $\begin{array}{c}-0.0729 \\
(0.5755) \\
{[-0.1267]}\end{array}$ & $\begin{array}{c}-1278.747 \\
(715.616) \\
{[-1.7869]}\end{array}$ \\
\hline $\mathrm{D}(\mathrm{ERP}(-2))$ & $\begin{array}{c}-0.0881 \\
(0.0304) \\
{[-2.8904]}\end{array}$ & $\begin{array}{c}-2.5503 \\
(0.7504) \\
{[-3.3985]}\end{array}$ & $\begin{array}{c}-0.2801 \\
(0.5643) \\
{[-0.4963]}\end{array}$ & $\begin{array}{c}331.4577 \\
(701.643) \\
{[0.4724]}\end{array}$ \\
\hline $\mathrm{D}(\operatorname{VIX}(-1))$ & $\begin{array}{r}\mathbf{0 . 0 0 5 7 7} \\
(0.0012) \\
{[4.6215]}\end{array}$ & $\begin{array}{c}-0.1858 \\
(0.0307) \\
{[-6.0492]}\end{array}$ & $\begin{array}{c}-0.1145 \\
(0.0231) \\
{[-4.9591]}\end{array}$ & $\begin{array}{c}-68.004 \\
(28.728) \\
{[-2.3671]}\end{array}$ \\
\hline $\mathrm{D}(\mathrm{VIX}(-2))$ & $\begin{array}{r}\mathbf{0 . 0 0 2 7 0} \\
(0.0012) \\
{[2.1349]}\end{array}$ & $\begin{array}{c}0.01226 \\
(0.0311) \\
{[0.3938]}\end{array}$ & $\begin{array}{c}0.00502 \\
(0.0234) \\
{[0.2145]}\end{array}$ & $\begin{array}{c}-37.1579 \\
(29.1151) \\
{[-1.2762]}\end{array}$ \\
\hline $\mathrm{D}(\mathrm{ROCI}(-1))$ & $\begin{array}{c}-0.0036 \\
(0.0016) \\
{[-2.2782]}\end{array}$ & $\begin{array}{c}-0.0090 \\
(0.0393) \\
{[-0.2299]}\end{array}$ & $\begin{array}{c}-0.0184 \\
(0.0295) \\
{[-0.6227]}\end{array}$ & $\begin{array}{c}76.982 \\
(36.792) \\
{[2.0921]}\end{array}$ \\
\hline $\mathrm{D}(\mathrm{ROCI}(-2))$ & $\begin{array}{c}-0.0048 \\
(0.0015) \\
{[-3.0634]}\end{array}$ & $\begin{array}{c}-0.0951 \\
(0.0391) \\
{[-2.4286]}\end{array}$ & $\begin{array}{c}0.0008 \\
(0.0294) \\
{[0.0260]}\end{array}$ & $\begin{array}{c}53.6112 \\
(36.6330) \\
{[1.4634]}\end{array}$ \\
\hline
\end{tabular}


Table 4. VAR Results. (Continued) $\mathrm{D}$ (ERP) $\quad \mathrm{D}$ (VIX) $\quad \mathrm{D}$ (ROCI) $\mathrm{D}(\mathrm{OF})$

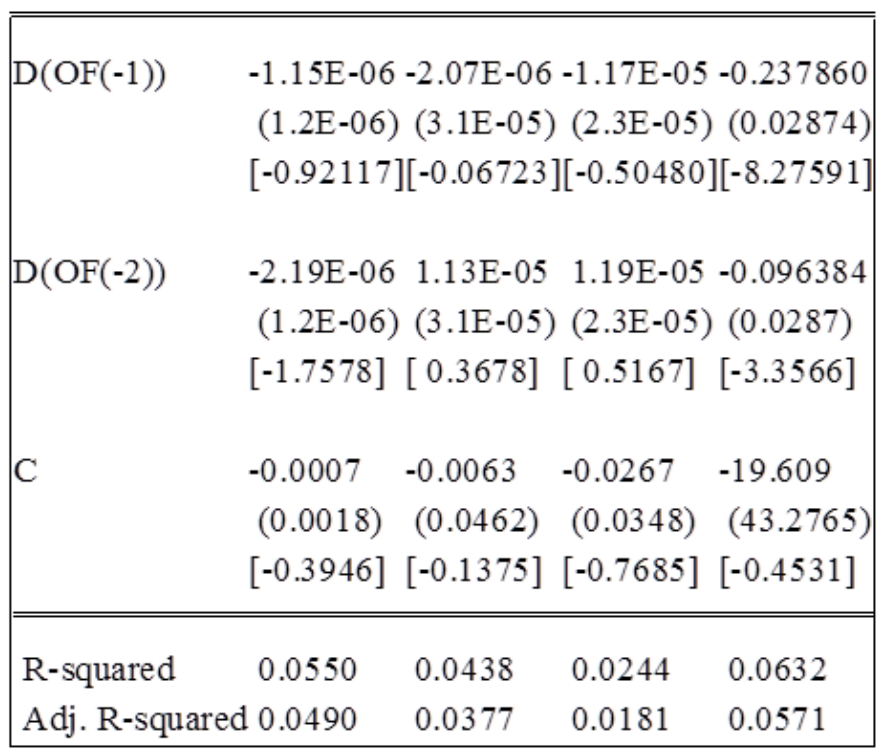

Source: Own Estimations with Data from Bloomberg and UBS.

Figure 5. Impulse Response Functions of the VAR Estimation
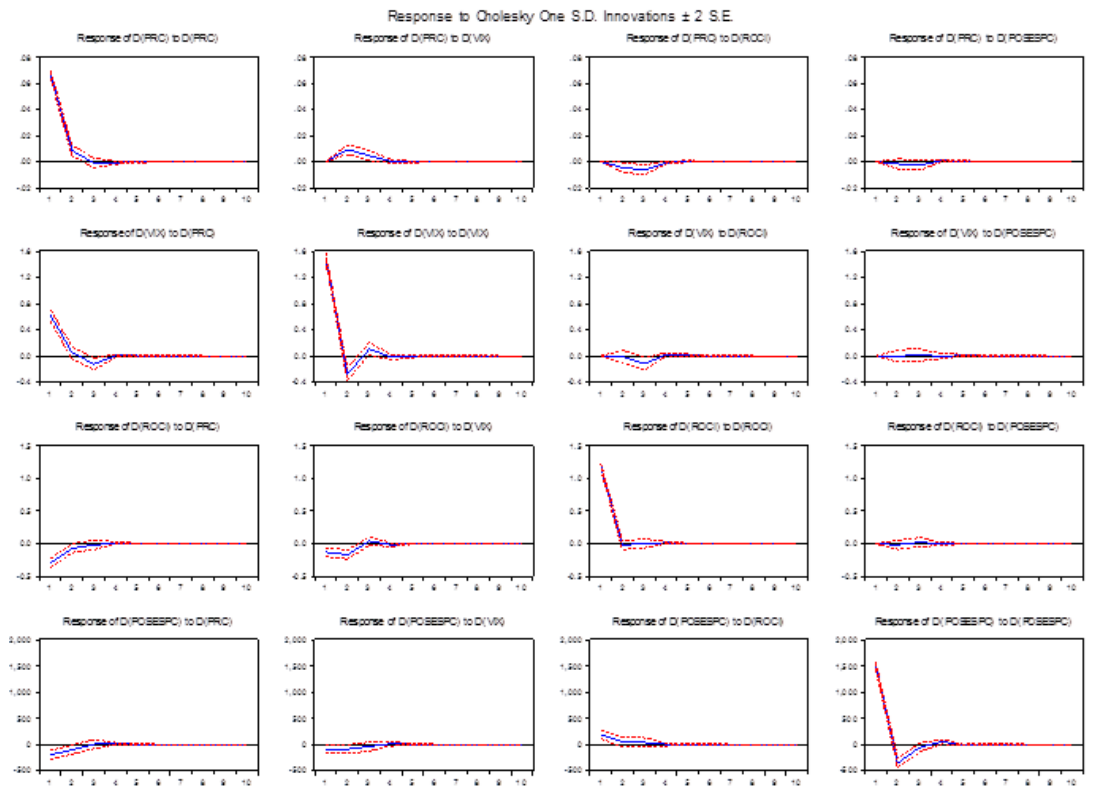

Source: Own Estimations with Data from Bloomberg and UBS. 
For example, the highest in magnitude coefficients affecting the ERP are from the VIX variable (financial volatility or distress variable). One of the advantages of estimated a VAR model is that, through variance decomposition of the error term, it is possible to apply what are known as 'impulse-response functions'. With these it is then possible to 'shock' the system by having a onestandard deviation increase in the residual component of the specific equation of the impulse-response analysis. Looking at the impulse-response functions applying Cholesky decomposition of variances show (Graph 5) that the highest response of the ERP variable comes from a 'shock' to the VIX variable, which again is the variable associated with financial volatility or uncertainty in the global markets. In other words, the ERP is more reactive (by having a positive and higher statistically significant coefficient) to the risk-aversion variable proxy by the VIX (forecast of financial volatility in the S\&P 500 Index). So, these results for the VAR estimation are in line with the previous results documented for the linear regression analysis (Equation 15), in a sense that the variables related to financial risk (EMBI, VIX) are the ones that statistically have a higher impact on the ERP dynamics. Additional analysis could be carried out adding other types of financial variables or applying regime-switching models, however, those issues are left for further research.

\section{Conclusions}

In the present research paper statistical relationships between the exchange rate risk premium (ERP) and other financial variables have been tested. The objective was to show how is it that this measure of risk-aversion proxy by the ERP was reactive to changes in financials conditions, more specifically variables related to sovereign risk, financial volatility and quantity of currency demanded. The ERP was extracted from risk-neutral densities implicit in currency option prices and currency option trading strategies (strangles and risk-reversals) following relevant literature about that topic. Linear regression methods and a VAR model were applied in order to estimate the possible statistical relationships between a set of chosen financial variables and the ERP. These variables were chosen considering information in the literature, which have considered the above mentioned financial variables, in addition to, empirical evidence of the existence of those statistical relationships, given the observed relationship between exchange rate dynamics and market uncertainty or volatility (also a fact in some documented research about this theme). According to the results from linear regressions, the variable EMBI is the one that has the highest impact on the ERP, given that, it has the one with the higher in magnitude statistically significant coefficient, which is also statistically different from the other estimated coefficients. The variable that follows (second highest impact given its order of magnitude) is the TED and then the VIX. The VAR estimations are consistent (qualitatively) with the results obtained from the linear regression models. It can be concluded, according to these results, that country credit sovereign risk (represented by the EMBI) in addition to systematic risk proxy by the TED and the VIX are the most important factors (drivers), which affect the ERP dynamics. It is important to point out that there are some limitations with the proposed specifications, for instance, other type of variables could have been included (e.g. commodity price variables). However, the specifications here considered are related to relevant methodologies seen in

the literature and the results may shed light on that part of the literature that 
documents about the relationships between FX markets and expectations of future risk or volatility, from an international finance paradigm. Further research about the theoretical justification of these empirical analysis are suggested for future and deeper understanding about this topic.

\section{References}

Abarca, G., Benavides, G. and Rangel, G. (2012). Exchange Rate Market Expectations and Central Bank Policy: The Case of the Mexican Peso-US Dollar from 2005-2009. Journal of Derivatives, Summer 2012, 19(4), pp. 70-90.

Benavides, G and Mora, I. (2008). Parametric vs. Non-Parametric Methods for Estimating Option Implied Risk-Neutral Densities: The Case of the Exchange Rate Mexican Peso - US Dollar. Ensayos Revista de Economía, 27, pp. 33-52.

Black, F. and Scholes, M. S. (1973). The Pricing of Options and Corporate Liabilities. Journal of Political Economy, 81, pp. 637-654.

Breeden, D., and Litzenberger, R. (1978). Prices of State-Contingent Claims Implicit in Option Prices. Journal of Business, 51, pp. 621-651.

Carlson, J. A. and Osler, C. L. (2003). Currency Risk Premiums: Theory and Evidence. Staff Reports 70, Federal Reserve Bank of New York. Seminar Paper. Centre for Economic Performance. LSE., London.

Castrén, O. (2005). Estimating and Analyzing Currency Options Implied Risk-Neutral Density Functions for the Largest New EU Member Status. European Central Bank. Working Paper No. 440.

Cooper, N., and Talbot, J. (1999). The Yen/Dollar Exchange Rate in 1998: Views from Options Markets. Bank of England Quarterly Bulletin. pp. 68-77, February.

Díaz de León, A., and Casanova, M. E. (2004). Expectativas del Mercado Implícitas en los Precios de Instrumentos Derivados: Aplicaciones al Mercado Cambiario y Petrolero. Banco de México. Documento de investigación No. 200401.

Engle, C. (1992). The Risk Premium and the Liquidity Premium in Foreign Exchange Rate Markets. International Economic Review. 33(4). November 1992.

Engle, C. (2012). The Real Exchange Rate, Real Interest Rates, and the Risk Premium. National Bureau of Economic Research (NBER) Working Paper No. 17116.

Evans, M. and Lyons, R. K. (2002). Order Flow and Exchange Rate Dynamics. Journal of Political Economy. February 2002. 110, pp. 369-379.

Garman, M. B., and Kohlhagen, S. W. (1983). Foreign Currency Option Values. Journal of International Money and Finance, 2, pp. 231-37.

Frankel, J. A, and Chinn, M. D. (1993). Exchange Rate Expectations and the Risk Premium: Tests for a Cross-section of 17 currencies. Review of International Economics. 1 (2), pp. 136-144.

Hakkio, C. S and A. Sibert (1995). The Foreign Exchange Risk Premium: Is It Real? Journal of Money, Credit and Banking. 27(2), May, 1995.

Hull, J. C. (2013). Options, Futures and Other Derivatives. Prentice Hall. $9^{t h}$ edition.

Malz, A. M. (1997). Estimating the Probability Distribution of the Future Exchange Rate from Option Prices. Journal of Derivatives, 5, pp. 18-36.

Shimko D., (1993). Bounds of Probability. Risk Magazine, 6, pp. 33-37. 